\title{
Chromosomal organization and phylogenetic relationships in Hypochaeris species (Asteraceae) from Brazil
}

\author{
Claudete de Fátima Ruas ${ }^{1}$, André L.L. Vanzela ${ }^{1}$, Melissa O. Santos ${ }^{1}$, Jeferson N. Fregonezi ${ }^{1}$, \\ Paulo Maurício Ruas ${ }^{1}$, Nelson I. Matzenbacher ${ }^{3}$ and Margarida L.R. de Aguiar-Perecin ${ }^{2}$ \\ ${ }^{1}$ Universidade Estadual de Londrina, Departamento de Biologia Geral, Londrina, PR, Brazil. \\ ${ }^{2}$ Escola Superior de Agricultura Luiz de Queiroz, Departamento de Genética, Piracicaba, SP, Brazil. \\ ${ }^{3}$ Universidade Federal do Rio Grande do Sul, Departamento de Genética, Porto Alegre, RS, Brazil.
}

\begin{abstract}
The association of cytogenetic and molecular techniques has contributed to the analysis of chromosome organization and phylogeny in plants. The fluorochrome GC-specific $\mathrm{CMA}_{3}$, fluorescent in situ hybridization (FISH) and RAPD (Random Amplified Polymorphic DNA) markers were used to investigate chromosome structure and genetic relationships in Hypochaeris (Asteraceae). Seven species native to South America, and two species introduced from Europe (H. glabra and Hypochaeris sp) were studied. FISH with rDNA probes identified one or two loci of 18S-5.8S-25S rDNA in the South American Hypochaeris species and one locus in the European species. Only one 5S rDNA locus was seen in all species studied. Blocks of GC-rich heterochromatin (CMA-positive bands) associated to 18S-5.8S-25SrDNA loci were detected in all species investigated. Co-location of 5S rDNA and CMA bands was also observed, except for three South American species and Hypochaeris sp. In two South American species, additional CMA bands not related to rDNA were observed on the long arm of chromosome 2, near to the centromere. Hypochaeris glabra exhibited additional CMA-positive signals distributed at pericentromeric regions, on the short arms of all chromosomes. A total of 122 RAPD markers were used to determine the genetic relationships among species. The level of polymorphism was very high, revealing two genetic groups comprising the South American and the European species, thus supporting a previous hypothesis of monophyly of the South American Hypochaeris species. The coefficients of genetic similarity between European and South American species were 0.35 , on average. Polymorphism was also high within the two groups. The genetic associations observed with RAPD markers were consistent with chromosome characteristics. Species carrying similar distribution of 45S rDNA loci and CMA-positive signals were included in the same group revealed by RAPDs. Cytogenetic and molecular data support the view that not only chromosome rearrangements, but also changes in DNA sequence took place during the diversification of the South American Hypochaeris species.
\end{abstract}

Key words: chromosome banding, FISH, Hypochaeris, phylogenetic relationship, RAPD.

Received: October 3, 2003; Accepted: August 16, 2004.

\section{Introduction}

The genus Hypochaeris (Asteraceae) is represented by around 60 species occurring in two major areas of distribution, comprising the Mediterranean region and South America. While the Mediterranean group includes about 13 species, the South American species are more numerous with around 50 species (Stuessy, 2001). Species relationships within the genus have been investigated in several studies. Stebbins (1971) suggested, on the basis of distinct chromosome characterists, that the Mediterranean was the primary center of origin and that South America represents the center of diversification of the genus. Cytogenetic stud-

Send correspondence to Claudete de Fátima Ruas. Universidade Estadual de Londrina, Departamento de Biologia Geral, 86051-990 Londrina, PR, Brazil. E-mail: ruas@ sercomtel.com.br. ies have shown a basic chromosome number of $x=3,4,5$ and 6 associated with symmetric karyotypes that characterizes the European Hypochaeris species (Stebbins, 1971; Cerbah et al., 1995, 1998a; Ruas et al., 1995). On the other hand, the South American species have a basic chromosome number of $\mathrm{x}=4$ and highly asymmetric and bimodal karyotypes (Stebbins, 1971; Barghi et al., 1989; Ruas et al., 1995). According to Stebbins (1971), asymmetric karyotypes would have originated through changes occurred in less complex chromosome sets, thus, the South American Hypochaeris species would have derived from European species (Siljak-Yakovlev, 1994; Cerbah et al., 1995, 1998a; Ruas et al., 1995).

Differences on chromosome size and satellite distribution have been observed among Hypochaeris species 
(Ruas et al., 1995; Cerbah et al., 1995, Cerbah et al., 1998a). Analyses of DNA content revealed a C-value varying from 1.68 to $8.10 \mathrm{pg}$ and, with few exceptions, there was no significant correlation between AT or GC content, suggesting that variability in genome sizes is a consequence of differences in the content of interspersed repetitive DNA sequences (Cerbah et al., 1995, 1999).

Recently, fluorescent in situ hybridization (FISH) has been the method of choice for assigning DNA sequences to chromosomes. The technique is specially appropriated to understand the chromosomal organization and to determine the physical distribution of specific DNA sequences on the chromosomes (Heslop-Harrison, 2000). Differences in number and distribution of $45 \mathrm{~S}$ and $5 \mathrm{~S}$ rDNA loci among related species have proven to be suitable to study genome evolution and species relationships in plants such as Calycadenia (Baldwin, 1993), Hordeum (Leitch and Heslop-Harrison, 1993), Aegilops (Castilho and Heslop-Harrison, 1995), Vigna (Galasso et al., 1998) and Clivia (Ran et al., 2001). Application of FISH to determine the distribution of $45 \mathrm{~S}$ and $5 \mathrm{~S}$ rDNA loci on Hypochaeris chromosomes, combined with fluorochrome banding, suggested that chromosome rearrangments such centric shifts and centric fusions, transposition, and inactivation of rDNA have occurred during the evolution of European and South American species of Hypochaeris (Cerbah et al., 1998a). These rearrangements were also concluded to be implicated in the reduction of rDNA loci in the genus.

Major advances on molecular techniques have permitted a better understanding of genome structure in Angiosperms. Recently, molecular systematic analysis has been used for phylogenetic studies within the genus Hypochaeris (Cerbah et al., 1999; Samuel et al., 1999). Sequence analyses of nuclear ITS regions and chloroplast trnL-F intron, trnL/trnF spacer and matK sequences, carried out to assess phylogenetic relationships among European and South American species of Hypochaeris, revealed that, except for $H$. Robertia, the clades formed by the ITS and the combined trees agree with sections previously stablished for the genus on the basis of morphological and cytological studies (Cerbah et al., 1999; Samuel et al., 1999, 2003). These observations provided evidence for monophyly of the South American species, which would have evolved from a single introduction of European progenitors rather than from $H$. robertia, as previously suggested (Barghi et al., 1989).

Among the different classes of molecular markers applied to assess genetic variation and taxonomic relatedness between plant groups, random amplified polymorphic DNA (RAPD) (Wesh and McClelland, 1990; Williams et al., 1990) has proved to be particularly appropriated. The technique is based on DNA amplification using 10-mer oligonucleotides in a PCR (Polymerase Chain Reaction). It produces a large number of easily generated markers without the need of previous knowledge of the genome. The success of RAPD markers for taxonomic and evolutionary studies has been observed in several plant species such as Stylosanthes (Kazan et al., 1993), Malus (Dunemann et al., 1994), Actinidia (Cipriani et al., 1996), Pisum (Hoey et al., 1996), Vigna (Santala et al., 1998) and Ananas (Ruas et al., 2001).

Considering the need for more studies on the Brazilian group of South American Hypochaeris species, the present work associated chromosome analysis, using FISH with 45S and 5S rDNA probes and fluorochrome banding, with RAPD makers to evaluate the interspecific relationships between seven Brazilian and two introduced European species of Hypochaeris. The phylogenetic schema was compared with the mechanisms proposed for chromosome evolution in the genus. Moreover, the karyotype of $H$. grisebashii is described here for the first time.

\section{Materials and Methods}

The specimens studied include seven species native to the Brazilian flora of the South American Hypochaeris and one species (H. glabra) introduced from Europe. An additional species (Hypochaeris sp) was also studied. Plant material used for the analysis of Hypochaeris sp was obtained from cypselae collected from plants of a population of $H$. radicata for which no karyotype analysis was available. Information about the origin of the species is summarized in Table 1. Voucher-specimens are preserved in the Herbarium of the Botanic Department of the Universidade Federal do Rio Grande do Sul (ICN), Porto Alegre, Rio Grande do Sul, Brazil.

\section{Chromosome preparations}

Root-tip meristems obtained from potted plants were pre-treated with $0.1 \%$ colchicine at room temperature for $1 \mathrm{~h}$

Table 1 - Chromosome numbers and collection sites of Hypochaeris species investigated.

\begin{tabular}{|c|c|c|}
\hline Species & $2 n$ & Collection sites \\
\hline $\begin{array}{l}\text { H. brasiliensis (Less) Benth et } \\
\text { Hook }\end{array}$ & 8 & $\begin{array}{l}\text { Guaíba, RS; } \\
\text { Curitiba, PR; } \\
\text { Piracicaba, SP }\end{array}$ \\
\hline H. grisebashii Cabr. & 8 & Guaíba, RS \\
\hline H. megapotamica Cabr. & 8 & $\begin{array}{l}\text { Guaíba and Capão da } \\
\text { Canoa, RS }\end{array}$ \\
\hline $\begin{array}{l}\text { H. microcephala (Sch.-Bip) Cabr. } \\
\text { var. albiflora (O.K.) Cabr. }\end{array}$ & 8 & Guaíba, RS \\
\hline $\begin{array}{l}\text { H. microcephala (Sch.-Bip) Cabr. } \\
\text { var. microcephala (O.K.) Cabr. }\end{array}$ & 8 & Guaíba, RS \\
\hline H. pampasica Cabr. & 8 & Guaíba, RS \\
\hline H. rosengurttii Cabr. & 8 & Guaíba, RS \\
\hline H. variegata Baker & 8 & Guaíba, RS \\
\hline H. glabra L. & 8 & $\begin{array}{l}\text { Curitiba and Ponta } \\
\text { Grossa, PR }\end{array}$ \\
\hline Hypochaeris sp. & 10 & Capão da Canoa, RS \\
\hline
\end{tabular}

${ }^{\text {a }}$ The abbreviations following collection sites correspond to Brazilian states: RS = Rio Grande do Sul; PR = Paraná; SP = São Paulo. 
and $30 \mathrm{~min}$ and then fixed in ethanol-acetic acid 3:1 for at least $12 \mathrm{~h}$. Chromosome identification was carried out for Hypocheris sp and for H. grisebashii, using the Feulgen staining method, as previously described by Ruas et al. (1995).

Chromosome preparations for FISH and chromomycin $\mathrm{A}_{3}$ banding were obtained as described by Schwarzacher et al. (1980). Briefly, pre-treated root-tips were washed twice in citrate buffer $(0.01 \mathrm{M}$ citric acid-sodium citrate, $\mathrm{pH}$ 4.6) and macerated in enzyme solution ( $2 \%$ cellulase $(\mathrm{w} / \mathrm{v})$ and $20 \%$ pectinase $(\mathrm{v} / \mathrm{v})$ at $37^{\circ} \mathrm{C}$ for $2 \mathrm{~h}$. After enzymatic treatment, the roots were washed in citrate buffer and the cells were dissociated in a drop of $45 \%$ acetic acid.

\section{In situ hybridization}

The ribosomal probes pTa71 and pTa794, isolated from T. aestivum (Gerlach and Bedbrook, 1979; Gerlach and Dyer, 1980) were used to locate the position of the $45 \mathrm{~S}$ and $5 \mathrm{~S}$ rDNA sites on the chromosomes. The probes were labeled with biotin-14-dATP by nick translation (Bio Nick, Gibco). FISH was carried out following the methods of Heslop-Harrisson et al. (1991) and Cuadrado and Jouve (1994) with minor modifications. The slides were incubated in $100 \mu \mathrm{g} / \mathrm{mL}$ DNase-free RNase in 2x SSC (0.03 M sodium citrate and $0.3 \mathrm{M}$ sodium chloride) for $1 \mathrm{~h}$ at $37^{\circ} \mathrm{C}$, washed for $5 \mathrm{~min}$ in each 2x SSC plus 4\% paraformaldehyde and 2x SSC, dehydrated through an ethanol series, and air- dried. The labeled rDNA probes (100-200 ng/slide) were mixed with $50 \%$ formamide, $10 \%(\mathrm{w} / \mathrm{v})$ polyethylenoglycol, $0.3 \%$ (w/v) sodium dodecyl sulfate, $300 \mathrm{mg} / \mathrm{mL}$ calf thymus DNA, and 2x SSC. The hybridization mixture was denatured at $70{ }^{\circ} \mathrm{C}$ for $10 \mathrm{~min}$ and immediately chilled on ice. Then the slides were loaded with $30 \mu \mathrm{L}$ of probe mixture, denatured at $90^{\circ} \mathrm{C}$ for $10 \mathrm{~min}$, transferred to $50{ }^{\circ} \mathrm{C}$ for $10 \mathrm{~min}$ and to $38^{\circ} \mathrm{C}$ for $10 \mathrm{~min}$. Hybridization was performed overnight at $37{ }^{\circ} \mathrm{C}$ in a moist chamber. Posthybridization washes were done as described by Cuadrado and Jouve (1994). The hybridization sites were detected with avidin-FITC conjugate $(5 \mu \mathrm{L} / \mathrm{mg} / \mathrm{mL})$ in $5 \%$ bovine serum albumin (BSA) at $37^{\circ} \mathrm{C}$ for $1 \mathrm{~h}$. Chromosomes preparations were counterstained with $1 \mu \mathrm{L}(2.5 \mu \mathrm{L} / \mathrm{mL})$ propidium iodide for $30 \mathrm{~min}$, mounted in $20 \mu \mathrm{L}$ of antifade solution (Vectashield H1000, Vector Laboratories). Preparations were examined with a Nikon Labophot microscope and photographed on Kodak 400 Proimage film.

\section{Chromomycin $\mathrm{A}_{3}$ banding}

Chromosome preparations aged for three days were incubated in $45 \%$ acetic acid at $60{ }^{\circ} \mathrm{C}$ for $10 \mathrm{~min}$, washed in double-distilled water and treated with $5 \% \mathrm{Ba}(\mathrm{OH})_{2}$ for $5 \mathrm{~min}$ at room temperature. Preparations were then incubated in $2 \mathrm{x} \mathrm{SSC}$ at $60^{\circ} \mathrm{C}$ for $1 \mathrm{~h}$ and $20 \mathrm{~min}$, washed in double-distilled water, and air-dried. Three-day-old slides were incubated in McIlvaine buffer $(0.1 \mathrm{M}$ citric acid plus $0.2 \mathrm{M}$ $\mathrm{Na}_{2} \mathrm{HPO}_{4} 7 \mathrm{H}_{2} \mathrm{O}, \mathrm{pH}$ 7.0) for $10 \mathrm{~min}$ and stained with $\mathrm{CMA}_{3}(0.5 \mathrm{mg} / \mathrm{mL}$ in McIlvaine buffer plus $2.5 \mathrm{mM}$
$\mathrm{MgCl}_{2}$ ) for $1 \mathrm{~h}$ and $30 \mathrm{~min}$ in a dark chamber. The preparations were then mounted in 1:1 (v/v) glycerol:McIlvaine buffer and the slides aged for another three days. Metaphases were examined with a Nikon microscope using a $\mathrm{CMA}_{3}$ selective filter (425-445 nm) and photographed on Kodak Tmax 100 film.

\section{DNA extraction and RAPD amplification}

Genomic DNA was isolated from young leaves of at least five individual plants of each species using the CTAB (cetyltrimethyl-ammonium bromide) procedure (Doyle and Doyle, 1989) with modifications, as previously described (Ruas et al., 2001).

Amplification reactions were carried out in volumes of $15 \mu \mathrm{L}$ containing 1X Taq polymerase buffer $(10 \mathrm{mM}$ Tris- $\mathrm{HCl} \mathrm{pH} 8.3 ; 50 \mathrm{mM} \mathrm{KCL}) ; 1.5 \mathrm{mM} \mathrm{MgCl}_{2} ; 0.1 \mathrm{mM}$ each of dATP, dTTP, dCTP, and dGTP (Pharmacia), $4 \mathrm{mM}$ of 10-mer arbitrary primers (Operon Technologies); $1 \mathrm{U}$ of Taq DNA polymerase (Pharmacia); and $20 \mathrm{ng}$ of template DNA, using a PTC-200 (MJ Research) thermal cycler with the same cycling parameters as reported by Ruas et al. (2001). Amplification products were resolved in 1.2\% metaphor agarose (FMC) in 1x TAE buffer $(40 \mathrm{mM}$ Trisacetate; $1 \mathrm{mM}$ EDTA, $\mathrm{pH} 8.0$ ) for $3 \mathrm{~h}$ at $120 \mathrm{~V}$. Gels were stained with ethidium bromide, visualized under UV light, photographed with a video camera and stored in a microcomputer for later analysis.

\section{Data analysis}

DNA markers were scored for the presence (1) or absence (0) of homologous DNA bands. The genetic similarities were estimated using the Dice coefficient of the NTSYS package (Numerical Taxonomy and Multivariate Analysis for personal computer), version 2.1 (Rohlf, 2000). A dendrogram was constructed using the UPGMA (unweighted pair-group method using arithmetic averages). The values of the bootstrap method, employed to evaluate the reliability of tree topology, were calculated with 1000 replicates using the BOOD software, version 3.0 (Coelho, 2001). The cophenetic coefficient between the genetic similarity matrix and the dendrogram was computed using an appropriate routine of the NTSYS-pc software. The significance of the cophenetic correlation was determined by using the Mantel correspondence test (Mantel, 1967).

\section{Results and Discussion}

\section{Karyotype analysis of $H$. grisebashii and Hypochaeris sp.}

Chromosome analysis of $H$. grisebashii was performed for the first time. The karyotype formula is $2 n=8=$ $4 \mathrm{~m}+4 \mathrm{st}$, with the same bimodal and asymmetric pattern that characterizes the South American Hypochaeris species analyzed so far (Stebbins, 1971; Ruas et al., 1995; Cerbah et al., 1995; 1998a). The size of the chromosomes varied from 
2.11 to $5.93 \mu \mathrm{m}$, with the secondary constriction located on chromosome pair 3 near to the centromere. The total haploid length $(15.0 \pm 1.52 \mu \mathrm{m})$ was considerably smaller than in other South American species reported by Ruas et al. (1995). This difference suggests that structural alterations involving decrease of DNA content are still playing a role in the chromosome evolution of South American Hypochaeris species.

Chromosome measurements of Hypochaeris sp revealed a symmetrical karyotype with $2 \mathrm{n}=10=$ $8 m+2 s m-s a t$, following the pattern of European species. The specimens evaluated displayed morphological characters of $H$. radicata. For instance, all cypselae were rostrated and the trichomes at the involucral bracts exhibited specific morphology and distribution only found in $H$. radicata. However, most investigations reported $2 \mathrm{n}=8$ chromosomes for $H$. radicata (Ruas et al., 1995; Cerbah et al.; 1998a). The only exception was reported by Hall and Parker (1995) who described, in an experimental population of $H$. radicata with $2 \mathrm{n}=8$, individuals presenting centric fission in one chromosome and then, heterozygous and homozygous individuals with $2 n=9$ and $2 n=10$ chromosomes, respectively. The findings of the present study show that the plants analyzed could represent a chromosome race of $H$. radicata and further studies are needed to substantiate this possibility.

\section{Localization of $45 S$ and $5 S$ ribosomal genes}

The results of FISH with rDNA $45 \mathrm{~S}$ and $5 \mathrm{~S}$ probes are shown in Figures 1 and 2, respectively, and summarized in Figure 5 and Table 2. All South American species showed one $45 \mathrm{~S}$ rDNA locus, identified around the secondary constriction of chromosome pair 3. This locus was pericentromeric in all species, except for $H$. rosengurttii (Figure1F), which had the hybridization signal in a terminal position and satellite of chromosome 3, revealing that paracentric inversions are implicated in changes in the position of $45 \mathrm{~S}$ rDNA loci of South American Hypochaeris. Analysis of metaphases and interphase nuclei revealed variation in the size of hybridization signals among species, suggesting differences in the number of gene copies at this locus. The signals were stronger, covering most of the chromosome arm (Figure $1 \mathrm{C}, \mathrm{E}, \mathrm{G}$ ), in $\mathrm{H}$. megapotamica, $\mathrm{H}$. pampasica and $H$. variegata than in $H$. brasiliensis, $H$. grisebashii and $H$. microcephala (Figure $1 \mathrm{~A}, \mathrm{~B}, \mathrm{D})$. Other hybridization signals were observed in a distal position on
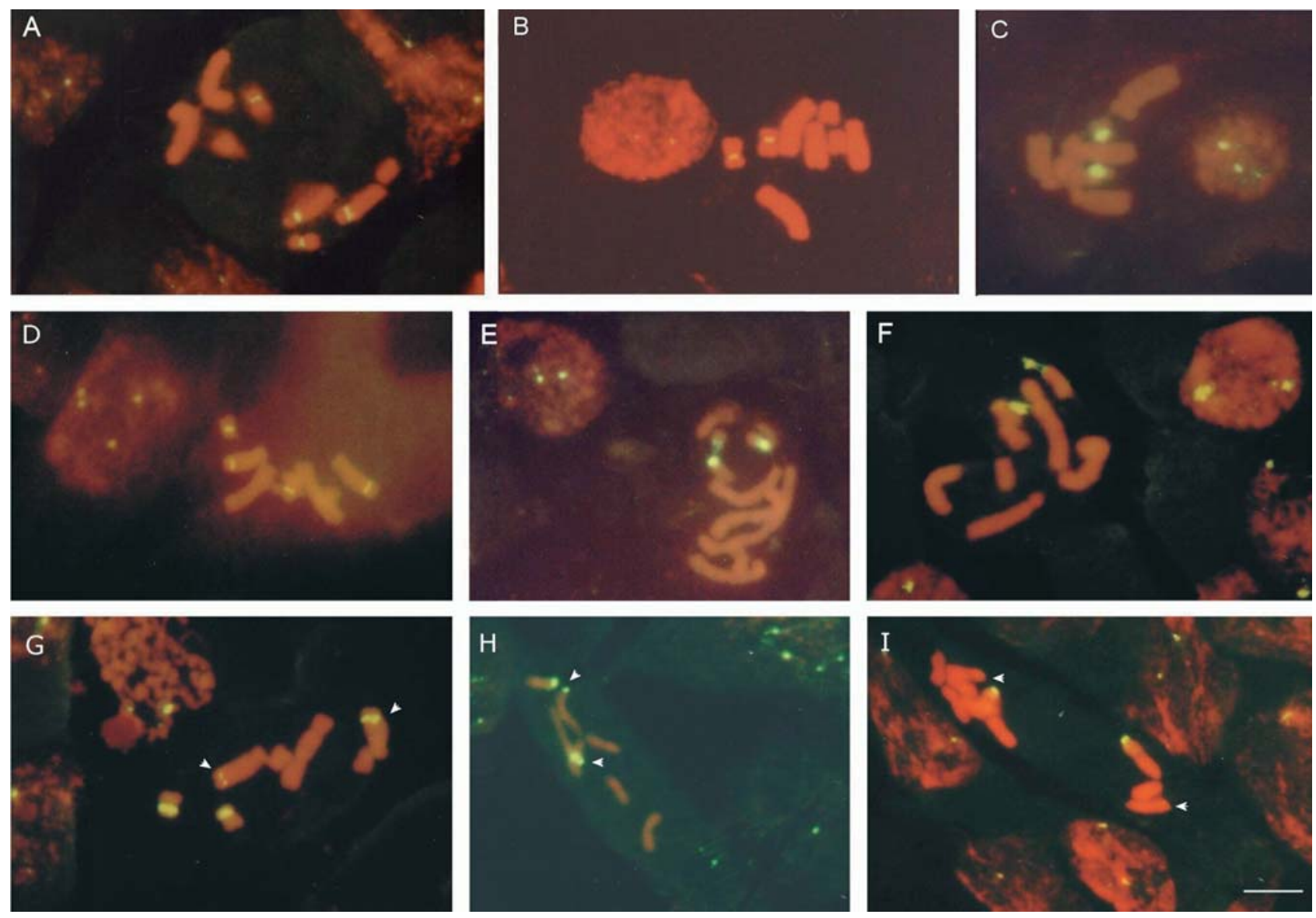

Figure 1 - Hybridization signals of mitotic metaphases probed with 45S rDNA genes in Hypochaeris species: (A) H. brasiliensis, (B) H. grisebashii, (C) H. megapotamica, (D) H. microcephala, (E) H. pampasica, (F) H. rosengurtii, $(\mathrm{G}) \mathrm{H}$. variegata (arrows = size polymorphism of $45 \mathrm{~S} \mathrm{rDNA}$ on chromosome pair 2), (H) H. glabra, and (I) Hypochaeris sp (arrows = weak 45S hybridization signals on chromosome 4) Bar $=6 \mu \mathrm{m}$. 

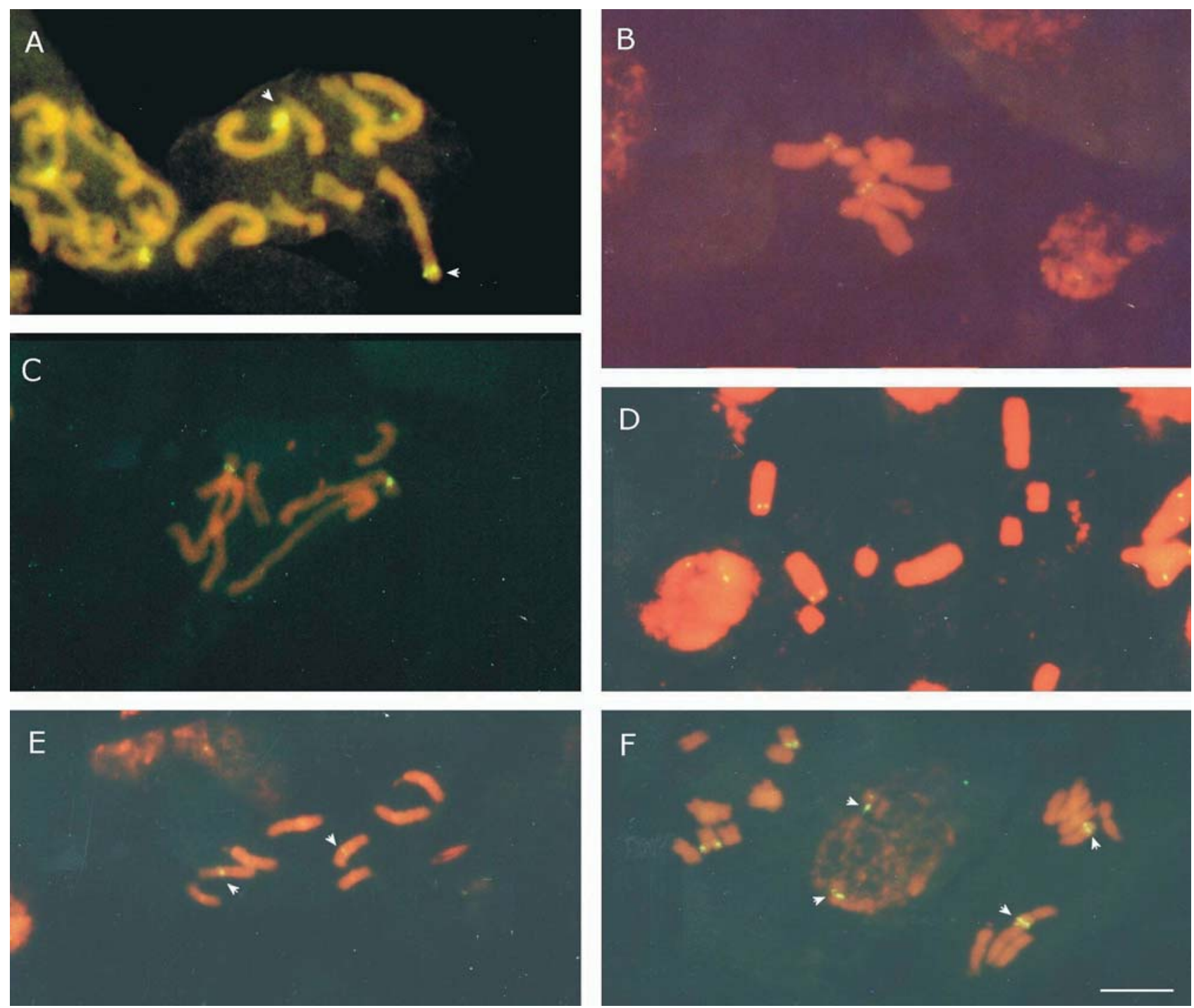

Figure 2 - Hybridization signals on mitotic metaphases probed with 5S rDNA genes in Hypochaeris species: (A) H. grisebashii, (B) H. microcephala, (C) H. rosengurtii, (D) H. variegata, (E) H. glabra, and (F) Hypochaeris sp. Bar $=6 \mu \mathrm{m}$.

the long arm of chromosome 2 in $H$. brasiliensis and in the two varieties of $H$. microcephala (Figure $1 \mathrm{~A}, \mathrm{D})$. Analysis of $H$. brasiliensis using silver impregnation (Ruas et al., 1995) detected transcriptional activities in both chromosome pairs 2 and 3. Hypochaeris variegata also displayed an additional $45 \mathrm{~S}$ rDNA locus in the same position of chromosome 2 (Figure $1 \mathrm{G}$ ). However, analysis of several individuals of this species showed that chromosome pair 2 is heteromorphic for the NOR locus, showing a conspicuous difference in the intensity of the FISH signals, which could be related to a reduced number of rDNA copies. The maximum number of nucleoli per nucleus was three in $H$. variegata (data not shown), suggesting that the NOR locus is transcriptionally inactive in one chromosome of pair 2 . However, this suggestion needs further investigation. Variation in the expression of $45 \mathrm{~S}$ rDNA loci was also reported in H. chilensis (Cerbah et al., 1998a). In H. variegata, the polymorphism observed in the size of the rDNA site could have originated by unequal crossing-over or by amplification and transposition of single rDNA copies, as suggested for other plant species (Schubert and Wobus, 1985; Garrido et al., 1994).

Cerbah et al. (1998a) suggested that the main 45S rDNA site for the South American species is located on chromosome 3 . We consistently observed one $45 \mathrm{~S}$ rDNA locus located on the short arm of chromosome 3 of all South American species investigated. Nevertheless, an additional 45S rDNA site appeared regularly on the long arm of chromosome 2 of $H$. brasiliensis, $H$. microcephala, and $H$. variegata. These data provide additional evidence to the observations of Cerbah et al. (1998a) that the 45S rDNA site located on chromosome 2 was conserved in some species and inactivated or eliminated during the karyotype evolution of Hypochaeris. 
The two populations of the Mediterranean species $H$. glabra showed the same chromosome number $(2 \mathrm{n}=8)$ reported by Ruas el al. (1995), in contrast with $2 \mathrm{n}=10$ reported for European populations of this species. FISH analysis revealed a single terminal $45 \mathrm{~S}$ rDNA locus on the small arm of chromosome 2 of $\mathrm{H}$. glabra Figure $1 \mathrm{H}$ ). In Hypochaeris sp, the $45 \mathrm{~S}$ rDNA locus was located at the end of the small arm of chromosome 3, besides an additional signal of weak intensity detected in a terminal position on the short arm of chromosome 4, in which a satellite was absent (Figure 1 I).

Variability in rDNA regions have been explained by translocation, as for instance in humans, in which translocations would have involve the NOR chromosomes 13, 14, 15, 21, and 22 (for review, see Hall and Parker, 1995). In some plant genomes, variability in the location of rDNA loci has been interpreted as a consequence of transposition of rDNA sequences, as suggested for Allium cepa (Schubert and Wobus, 1985). The same mechanism was proposed for $H$. radicata by Hall and Parker (1995). The authors suggested that the origin and stabilization of a fission rearrangement in individuals of $H$. radicata with $2 \mathrm{n}=$ 8 involved transposition of rDNA from the NOR region on chromosome 3 into the centromeric region of a fission derivative from chromosome 1 . In the present study, we could suppose that some rDNA sequences could have transposed from chromosome 3 to chromosome 4 of Hypochaeris sp. Considering the chromosome number $(2 \mathrm{n}=10)$ of the analyzed plants, we could also hypothesize that the karyotype of Hypochaeris sp was derived by chromosome rearrangements from a plant with $2 \mathrm{n}=8$ (possibly $H$. radicata).

Previous investigations in Hypochaeris showed one, two, or a maximum of three $45 \mathrm{~S}$ rDNA sites per haploid genome (Cerbah et al., 1995; Cerbah et al., 1998a). The intensity of hybridization signals was associated with the number of rDNA gene copies. In $H$. robertia, the presence of tiny signals was related with a low number of copies in each of the three $45 \mathrm{~S}$ rDNA loci and with the small genome of this species (Cerbah et al., 1995; 1998a). In the present study, the hybridization signals observed in the two $45 \mathrm{~S}$ rDNA loci of $H$. brasiliensis and $H$. microcephala (Figure 1 A, D) were brighter than that of the single locus of $H$. grisebashii (Figure 1 B). Indeed, chromosome measurements of $H$. grisebashii revealed a rather smaller haploid genome in this species, suggesting a possible loss of $45 \mathrm{~S}$ rDNA sequences that may be related to a lower DNA content.

We have confirmed the presence of a single cluster of 5S rDNA genes supporting the results reported by Cerbah et al. (1998a). In all South American species, the 5S rDNA clusters were in an intercalary position on the small arm of chromosome 2, as seen in Figures 2 (A-D) and 5. The regular distribution and the uniformity of the hybridization signals observed in the $5 \mathrm{~S}$ rDNA loci revealed that these clusters are more stable than $45 \mathrm{~S}$ rDNA clusters in the genome of South American Hypochaeris.

The European species H. glabra and Hypocheris sp showed different distribution of $5 \mathrm{~S}$ rDNA sites. Hypochaeris glabra revealed one 5S rDNA site, identified near to the centromere on the long arm of chromosome 3. Hypochaeris sp showed two closely adjacent 5S rDNA sites identified near the terminal region on short arm of chromosome 2 (Figure 2 E-F). These chromosome locations of the $5 \mathrm{~S}$ rDNA locus also differed from that reported by Cerbah et al. (1998a) for H. glabra and H. radicata, where the 5S rDNA genes were located at an intercalary position, on the short arm of chromosome 4 and on the long arm of chromosome 2, respectively. These results support the hypothesis that structural rearrangements, such as centric shift may have occurred in populations of European species established in South America.

\section{Chromomycin $\mathrm{A}_{3}$ Banding}

The chromomycin A3 banding patterns were comparatively analyzed as summarized in Table 2 . In all species, CMA-positive bands were found associated with regions identified as 45S rDNA sites by FISH (Figure 3 A-I and Figure 5). The association between CMA-positive bands

Table 2 - Distribution of $\mathrm{CMA}_{3}$ positive bands and 45S and 5S rDNA loci per haploid genome of Hypochaeris species.

\begin{tabular}{|c|c|c|c|}
\hline Species & $\begin{array}{l}\text { Number and distribution of } \mathrm{CMA}_{3} \text { bands } \\
\text { associated to } 45 \mathrm{~S} \text { rDNA }\end{array}$ & $\begin{array}{l}\text { Number and distribution of } \mathrm{CMA}_{3} \\
\text { bands associated to } 5 \mathrm{~S} \text { rDNA }\end{array}$ & $\begin{array}{l}\text { Number and distribution of additional } \\
\qquad \mathrm{CMA}_{3} \text { bands }\end{array}$ \\
\hline H. brasiliensis & 2 (SC of LA of pair 2 and SA of pair 3$)$ & $1(\mathrm{SA}$ of pair 2$)$ & - \\
\hline H. grisebashii & $1(\mathrm{SC} / \mathrm{SA}$ of pair 3$)$ & & $1(\mathrm{PC} / \mathrm{LA}$ of pair 2$)$ \\
\hline H.megapotamica & $1(\mathrm{SA}$ of pair 3$)$ & $1(\mathrm{SA}$ of pair 2$)$ & - \\
\hline H. microcephala & 2 (SC/LA of pair 2 and SC/SA of pair 3$)$ & $1(\mathrm{SA}$ of pair 2$)$ & - \\
\hline H. rosengurttii & 1 (SA of pair 3$)$ & - & - \\
\hline H. variegata & $2($ SA of pair 3$)$ & - & - \\
\hline H. glabra & 1 (sat of pair 2) & 1 (LA of pair 3$)$ & 4 (PC/SA of pairs $1-4)$ \\
\hline Hypochaeris sp & 1 (sat of pair 3 ) & $1(\text { SA of pair } 2)^{*}$ & - \\
\hline
\end{tabular}

$\mathrm{PC}=$ pericentromeric; $\mathrm{SC}=$ secondary constriction; $\mathrm{sat}=$ satellite; $\mathrm{SA}=$ short arm; $\mathrm{LA}=$ long arm.

* 5S rDNA not associated with CMA bands. 
and 45S rDNA loci was previously observed by Cerbah et al. $(1995 ; 1998 \mathrm{a})$ in European and South American Hypochaeris species. This distribution pattern of GC- rich heterochromatin has also been described in many other related or unrelated plant groups (Galasso et al., 1995, 1998; Fukui and Nakayama, 1996).

Co-location of 5S rDNA and $\mathrm{CMA}+$ bands was clearly observed in $H$. brasiliensis, $H$. megapotamica, both varieties of $H$. microcephala, $H$. pampasica and $H$. glabra (Figures 3 A, C, D, E, H and Figure 5), but this correspondence was not detected in the other species investigated, including Hypochaeris sp. Cerbah et al. (1998a) reported the co-location of 5S rDNA loci and CMA bands in South American and European species, except $H$. radicata. These findings need further investigation concerning the organization of 5S rDNA repeat units in Hypochaeris, to understand this CMA response.

Additional CMA-positive bands, not related to rDNA, were observed on the long arm of chromosome 2, near to the centromere, in $H$. grisebashii and $H$. pampasica (Figure 3 B, E). In H. glabra, additional bands exhibiting equilocal distribution were seen near to the centromere on the short arm of all chromosomes. (Figure $3 \mathrm{H}$ ). This pattern of CMA bands is totally different from that described by Cerbah et al. (1998a), for a European population of $H$. glabra where only one intercalary band was observed on the short arm of pair 4, besides the satellite-associated band. Cerbah et al. (1995) also detected a thin $\mathrm{CMA}_{3}$ band on the short arm of chromosome 1 in $H$. microcephala, which was absent in the populations analyzed in this study.

Determination of DNA content and DNA base composition showed little differences in GC percentage in Hypochaeris species (Cerbah et al., 1995), supporting the relatively homogeneous pattern of $\mathrm{CMA}_{3}$ blocks observed in the present study, especially in the South American species.

\section{Genetic relationships based on RAPD markers}

RAPD markers have been considered as suitable characters for genetic analysis since they allow to examine accumulated genetic differences that are important at various taxonomic levels. Molecular markers such as RAPDs are neutral characters with no known phenotypic effects (Aagaard et al., 1998) and therefore, they are excellent
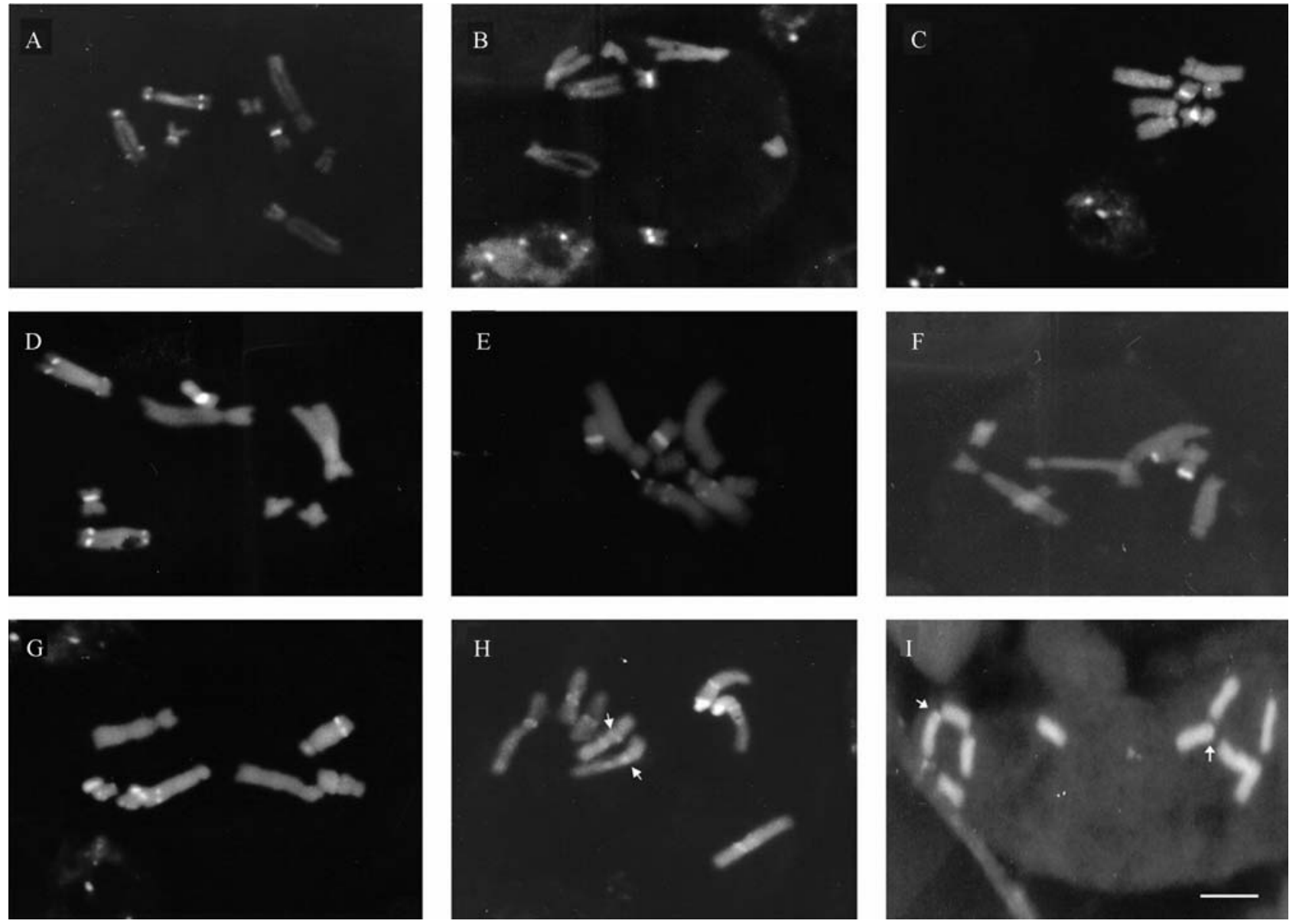

Figure 3 - Mitotic metaphases stained with chromomycin $\mathrm{A}_{3}$ showing the distribution of GC-rich heterochromatin in Hypochaeris species: (A) H. brasiliensis, (B) H. grisebashii, (C) H. megapotamica, (D) H. microcephala, (E) H. pampasica, (F) H. rosengurttii, (G) H. variegata, (H) H. glabra, and (I) Hypochaeris sp (arrows $=$ weak $\mathrm{CMA}_{3}$ bands). $\mathrm{Bar}=6 \mu \mathrm{m}$. 
tools for studying genetic variability of natural populations. Additionally, because RAPDs are randomly distributed over the entire genome, extensive amount of polymorphism can be detected.

RAPD markers were applied to identify intra- and interspecific variation and to evaluate the phylogenetic relationships among nine species of Hypochaeris. Ninety-eight RAPD primers were initially tested, to select those that were suitable in generating reproducible and polymorphic bands. Twenty-five primers were then selected and used for DNA amplification in all Hypochaeris species, rendering a total of 122 markers, 120 (98\%) of which were polymorphic. Figure 4 illustrates the electrophoresis profile obtained with primer OPS-10. The data matrix of genetic similarities and the dendrogram with the respective bootstrap values are illustrated in Table 3 and Figure 5, respectively. The value of cophenetic correlation $(\mathrm{r}=0.98)$ between the similarity matrix and the dendrogram indicates to which extent the clustering of genotypes accurately represents the estimates of genetic similarities among species. Cluster analysis associated the species under study into two major groups, comprising the South American and the European species, with a mean genetic similarity of only $34.7 \%$ (Table 3 ) and a $100 \%$ bootstrap support. These results are in agreement with the hypothesis of a monophyletic origin for the South American Hypochaeris species (Samuel et al. 1999; 2003).

The groups represented by the South American species showed a consistent association between molecular markers and karyotype features (Figure 5), showing substantial levels of polymorphism. The genetic similarity values ranged from $55 \%$ between $H$. microcephala var albiflora and $H$. pampasica to $79 \%$ between $H$. grisebashii

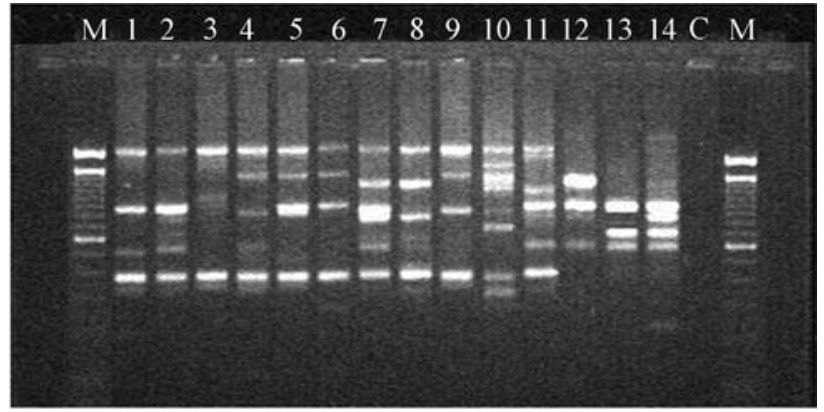

Figure 4 - Electrophoretic pattern of primer OPS-04 in Hypochaeris species: 1-3 $=H$. brasiliensis (populations of Guaíba, RS; Curitiba, PR and Piracicaba, SP), $4=H$. grisebashii, 5-6 $=H$. megapotamica (populations of Guaíba and Capão da Canoa, RS), $7=H$. microcephala var albiflora, $8=H$. microcephala var microcephala, $9=H$. pampasica, $10=H$. rosengurttii, $11=H$. variegata, $12-13=H$. glabra (populations of Curitiba and Ponta Grossa, PR) $14=$ Hypochaeris sp. $\mathrm{C}=$ Control, $\mathrm{M}=$ ladder (123 bp, Gibco).

and H. megapotamica. Based on the RAPDs, the South American species were divided into three subgroups (Figure 5). The first subgroup associated $H$. brasiliensis and $H$. microcephala, which also display similar chromosome characteristics, with an average of $68 \%$ genetic similarity. For instance, they both exhibit CMA bands and the $45 \mathrm{~S}$ rDNA loci at the same position on chromosomes 2 and 3. The second group associates $H$. grisebashii, $H$. megapotamica and H. pampasica with a $76 \%$ genetic similarity, on average. These species show the same distribution of the 45S rDNA genes, identified in the pericentromeric region on the small arm of chromosome 3 besides an additional CMA band observed on chromosome 2 of H. megapotamica and H. pampasica. The third subgroup associated $H$. rosengurttii and $H$. variegata with a

Table 3 - Similarity matrix generated from Dice coefficient based on 122 RAPD markers obtained for Hypochaeris species.

\begin{tabular}{|c|c|c|c|c|c|c|c|c|c|c|c|c|c|c|}
\hline Species & 1 & 2 & 3 & 4 & 5 & 6 & 7 & 8 & 9 & 10 & 11 & 12 & 13 & 14 \\
\hline 1. H. brasiliensis (RS) & 1.00 & & & & & & & & & & & & & \\
\hline 2. H. brasiliensis $(\mathrm{PR})$ & 0.85 & 1.00 & & & & & & & & & & & & \\
\hline 3. H. brasiliensis (SP) & 0.90 & 0.82 & 1.00 & & & & & & & & & & & \\
\hline 4. H. grisebashii (RS) & 0.68 & 0.62 & 0.71 & 1.00 & & & & & & & & & & \\
\hline 5. H. megapotamica (RS) & 0.67 & 0.61 & 0.69 & 0.79 & 1.00 & & & & & & & & & \\
\hline 6. H. megapotamica (RS) & 0.68 & 0.62 & 0.67 & 0.78 & 0.88 & 1.00 & & & & & & & & \\
\hline 7. H. microcephala var. albiflora (RS) & 0.71 & 0.64 & 0.69 & 0.59 & 0.61 & 0.67 & 1.00 & & & & & & & \\
\hline 8. H. microcephala var. microcephala (RS) & 0.71 & 0.64 & 0.69 & 0.62 & 0.66 & 0.70 & 0.88 & 1.00 & & & & & & \\
\hline 9. H. pampasica (RS) & 0.63 & 0.60 & 0.60 & 0.77 & 0.76 & 0.76 & 0.55 & 0.62 & 1.00 & & & & & \\
\hline 10. H. rosengurttii $(\mathrm{RS})$ & 0.65 & 0.58 & 0.68 & 0.72 & 0.72 & 0.69 & 0.67 & 0.65 & 0.67 & 1.00 & & & & \\
\hline 11. H. variegata $(\mathrm{RS})$ & 0.70 & 0.65 & 0.70 & 0.68 & 0.67 & 0.64 & 0.65 & 0.68 & 0.66 & 0.74 & 1.00 & & & \\
\hline 12. H. glabra (PR) & 0.32 & 0.37 & 0.32 & 0.23 & 0.29 & 0.24 & 0.38 & 0.38 & 0.25 & 0.26 & 0.32 & 1.00 & & \\
\hline 13. H. glabra (PR) & 0.27 & 0.40 & 0.37 & 0.24 & 0.29 & 0.24 & 0.36 & 0.35 & 0.23 & 0.32 & 0.38 & 0.81 & 1.00 & \\
\hline 14. Hypochaeris sp (RS) & 0.33 & 0.38 & 0.37 & 0.28 & 0.31 & 0.29 & 0.41 & 0.42 & 0.36 & 0.40 & 0.44 & 0.73 & 0.76 & 1.00 \\
\hline
\end{tabular}

The letters in parenthesis represent Brazilian states as described in Table 1. 


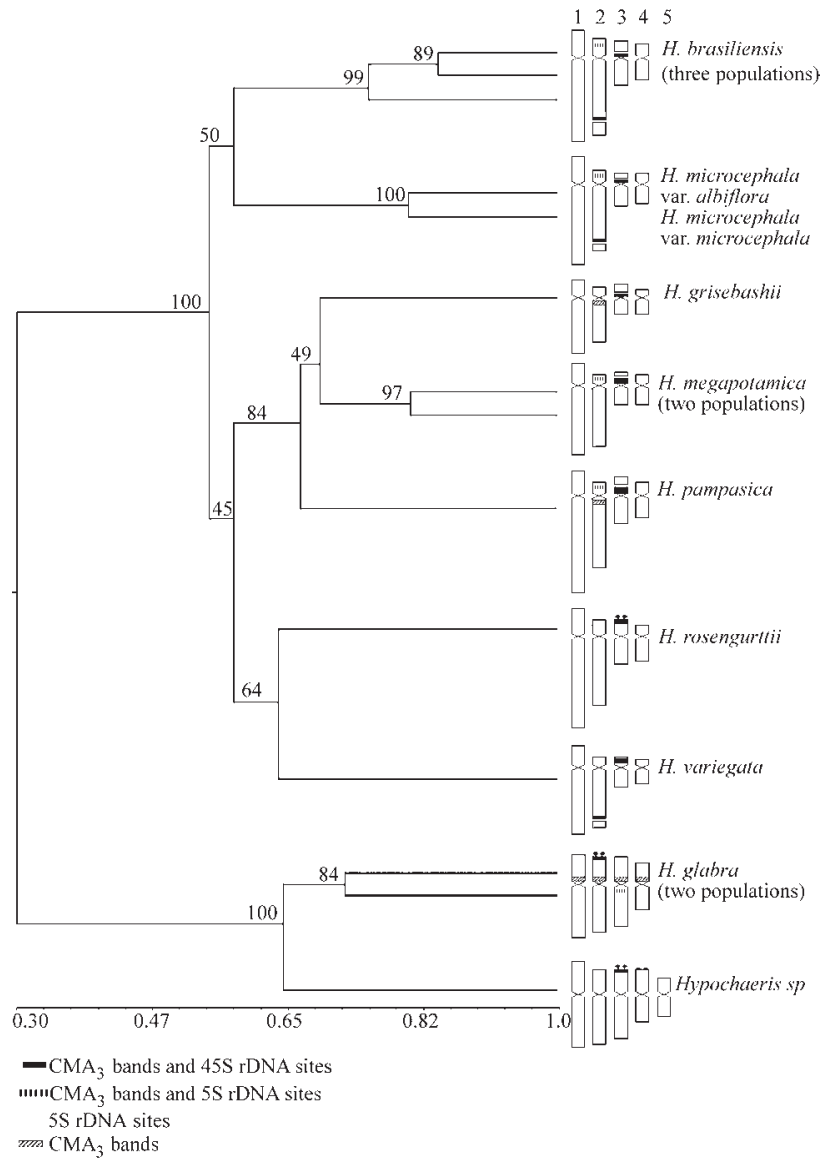

Figure 5 - Dendrogram showing the association between RAPD markers and chromosome data in Hypochaeris. The numbers above the branches are the boostrap values calculated for 1000 replications.

similarity of $74 \%$. However, in $H$. rosengurttii, the single locus of the $45 \mathrm{~S}$ rDNA clusters was located at the secondary constriction and adjacent satellites of chromosome 3, while $H$. variegata had the $45 \mathrm{~S}$ rDNA genes on chromosome pairs 2 and 3, like $H$. brasiliensis and $H$. microcephala.

The European species H. glabra and Hypochaeris sp (possible a cytotype of $H$. radicata), which were isolated from the South American group, showed an average genetic similarity of $74.5 \%$. Whereas these species are known to display symmetrical karyotypes, we detected a distinct distribution of $\mathrm{CMA}_{3}$ bands and 5S rDNA genes (Figures 2 E-F; 3 H-I; and 5).

RAPD markers also identified considerable levels of intraspecific variation. Analysis of three populations of $H$. brasiliensis showed a genetic similarity that ranged from $82 \%$ to $90 \%$ (Table 3 ). Similar levels of variation were documented between the two populations of $H$. megapotamica and between the two populations of $H$. glabra, which showed a genetic similarity of $88 \%$ and $81 \%$, respectively. The two varieties of $\mathrm{H}$. microcephala had a genetic similarity of $88 \%$. This pattern of intraspecific variation is com- mon for pioneer species, such as those of the genus Hypochaeris (Stuessy, 2001).

The importance of molecular phylogenetic studies to understand changes in plant genome organization and chromosome evolution has been emphasized in many works. Taxonomy and phylogenetic relationships of the genus Hypochaeris have been discussed based on a sequencing data set of ITS regions (Cerbah et al., 1998b; Samuel et al., 1999; 2003) and plastidial intergenic TrnL and mat-K sequences (Samuel et al., 1999; 2003). These authors suggested that South American Hypochaeris species constitute a monophyletic group that was probably derived from a single progenitor introduced from Europe. They also considered that $H$. maculata rather than $H$. robertia, as previously suggested by Barghi et al. (1989), is closer to the South American species than any other European species. Cerbah et al. (1995) showed that $H$. maculata has a high DNA content $(7.48 \mathrm{pg}$ ) when compared with the DNA content of the South American species (4.15 to $4.65 \mathrm{pg}$ ), suggesting that, in addition to chromosome rearrangements, which coordinated the changes in position and number of NOR genes, as suggested by Cerbah et al. (1998a), loss of DNA accompanied the origin and establishment of the South American karyotypes. Likewise, the pattern of genetic variation detected with RAPD markers is also consistent with changes in DNA repetitive elements, which are known to evolve more rapidly than single sequences (Wu et al., 1999).

The evolutionary dynamics of the $45 \mathrm{~S}$ rDNA sites points to some trends among South American species. It has been noted that while some species have two rDNA sites, the main locus is probably the one located on the small arm of chromosome 3, as suggested by Cerbah et al. (1998a). Paracentric inversion may have moved this site from terminal chromosome regions, as in $H$. rosengurttii, to a perhaps more stable pericentromeric position, as observed in all other species. Furthermore, differences detected in the hybridization signals suggest the occurrence of reduction in the number of $45 \mathrm{~S}$ rDNA copies at this site, implying that deletion of DNA sequences is also implicated in the diversification of genomes in the South American species.

The results obtained in the present work concerning karyotype features, chromosome location of $45 \mathrm{~S}$ rDNA loci and CMA-positive bands showed that the species diversification in Hypochaeris involved chromosome rearrangements, as previously reported (Ruas et al., 1995; Cerbah et al., 1995; 1998a). The nature of the RAPD markers also suggests that changes in DNA content may have resulted from amplification or deletion of repetitive DNA sequences. Genome diversification has involved considerable alteration of repetitive DNA sequence arrays in several groups of plants (Heslop-Harrison, 2000) and therefore, the variability of RAPD markers may represent a result of variation in different classes of repetitive DNA sequences among Hypochaeris species. 
The high genetic variability detected using RAPD and the correlation between cytogenetic and molecular markers give additional support to the idea that a major evolutionary pathway operated toward genome organization and karyotype differentiation, leading the separation of European and South American species of Hypochaeris.

\section{Acknowledgements}

This research was supported by Fundação de Amparo a Pesquisa do Estado de São Paulo-FAPESP (Proc. 98/01170-5), Fundação Araucária, PR (Proc. 111/2001) and $\mathrm{CNPq}$.

\section{References}

Aagaard JE, Krutovskii KV and Strauss SH (1998) RAPDs and allozymes exhibit similar levels of diversity and differentiation among populations and races of Douglas-fir. Heredity 81:69-78.

Baldwin BG (1993) Molecular phylogenetics of Calycadenia (Compositae) based on ITS sequences of nuclear ribosomal DNA: Chromosomal and morphological evolution reexamined. Amer J Bot 80:222-238.

Barghi N, Mugnier C and Siljak-Yakovlev S (1989) Karyological studies in some Hypochaeris ssp. (Compositae) from Sicily. Plant Syst Evol 168:49-57.

Castilho A and Heslop-Harrison JS (1995) Physical mapping of $5 \mathrm{~S}$ and $18 \mathrm{~S}-25 \mathrm{~S}$ rDNA and repetitive DNA sequences in Aegilops umbellulata. Genome 38:91-96.

Cerbah M, Coulaud J, Godelle B and Siljak-Yakovlev S (1995) Genome size fluorochrome banding, and karyotype evolution in some Hypochaeris species. Genome 38:689-695.

Cerbah M, Coulaud J and Siljak-Yakovlev S (1998a) rDNA organization and evolutionary relationship in the genus Hypochaeris (Asteraceae). The J Heredity 89:312-318.

Cerbah M, Souza-Chies T, Jubier MF, Lejeune B and Siljak-Yakovlev S (1998b) Molecular phylogeny of the genus Hypochaeris (Asteraceae). Mol Biol Evol 15:345-354.

Cerbah M, Coulaud J, Brown SC and Siljak-Yakovlev S (1999) Evolutionary DNA variation in the genus Hypochaeris (Asteraceae). Heredity 82:261-266.

Cipriani G, Di Bella R and Testolin R (1996). Screening RAPD primers for molecular taxonomy and cultivar fingerprinting in the genus Actinidia. Euphytica 90:169-174.

Coelho ASG (2001) BOOD - Avaliação de dendrogramas baseado em estimativas de distâncias/similaridades genéticas através do procedimento de bootstrap. v. 3.0. Departamento de Biologia Geral, Instituto de Ciências Biológicas, Universidade Federal de Goiás. Goiânia, GO, Brasil.

Cuadrado A and Jouve N (1994) Mapping and organization of highly-repeated DNA sequences by means of simultaneous and sequential FISH and C-banding in 6x-Triticale. Chrom Res 2:231-338.

Doyle JJ and Doyle JL (1987) A rapid DNA isolation procedure for small quantities of fresh leaf tissue. Phytoch Bull 19:1115 .

Dunemann F, Kahnau R and Schmidt H (1994) Genetic relationships in Malus evaluated by DNA fingerprint of cultivars and wild species. P Breeding 113:150-159.
Fukui K and Nakayama S (1996) Chromosome banding methods. In: Fukui $\mathrm{K}$ and Nakayama S (eds) Plant Chromosomes: Laboratory Methods. Boca Raton, New York, pp 123-153.

Galasso IT, Schmidt T, Pignone D and Heslop-Harrison JS (1995). The molecular phylogenetics of Vigna unguiculata (L.) Walp: The physical organization and characterization of 18S-5.8S-25S rDNA genes, 5S genes, telomere-like sequences, and a family of centromeric repetitive DNA sequences. Theor Appl Gen 91:928-935.

Galasso IT, Saponetti LS and Pignoni D (1998) Cytotaxonomic Studies in Vigna. IV. Variation of the number of active and silent rDNA sites in Vigna unguiculata populations. Caryologia 2:95-104.

Garrido MA, Jamilena M, Lozano R, Ruiz Rejon C, Ruiz Rejon M and Parker JS (1994) rDNA site polymorphism and NOR inactivation in natural populations of Allium schoenoprasum. Genetica 94:67-71.

Gerlach WL and Bedbrook JR (1979) Cloning and characterization of ribosomal RNA genes from wheat and barley. Nucl Acid Res 7:1869-1885.

Gerlach WL and Dyer TA (1980) Sequence organization of the repeating units in the nucleus of wheat which contain $5 \mathrm{~S}$ rRNA genes. Nucl Acid Res 8:4851-4855.

Hall KL and Parker JS (1995) Stable chromosome fission associated with rDNA mobility. Chrom Res 3:417-422.

Heslop-Harrison JS (2000) Comparative genome organization in plants: From sequences and markers to chromatin and chromosomes. The Plant Cell 12:617-635.

Heslop-Harrison JS, Schwarzacher T, Anamthawat-Jónsson K, Leitch AR, Shi M and Leitch IJ (1991) In situ hybridization with automated chromosome denaturation. Technique 3:109-115.

Hoey BK, Crowe KR, Jones VM and Polans NO (1996) A phylogenetic analysis of Pisum based on morphological characters, and allozyme and RAPD markers. Theor Appl Gen 92:92-100.

Kazan K, Manners JM and Cameron DF (1993) Genetic variation in agronomically important species of Stylosanthes determined using random amplified polymorphic DNA markers. Theor Appl Gen 85:882-888.

Leitch IJ and Heslop-Harrison JS (1993) Physical mapping of four sites of $5 \mathrm{~S}$ rDNA sequences and one site of the alphaamylase-2 gene in barley (Hordeum vulgare). Genome 36:517-523.

Mantel N (1967) The detection of disease clustering and a generalized regression approach. Cancer Res 27:209-220.

Ran Y, Hammett RWK, and Murray BG (2001) Phylogenetic analysis and karyotype evolution in the genus Clivia (Amaryllidaceae). Annals Bot 87:823-830.

Rohlf FJ (2000) NTSYS-pc Numerical Taxonomy and Multivariate Analysis System version 2.1 Owner manual.

Ruas CF, Ruas PM, Matzenbacher NI, Ross G, Bernini C and Vanzela ALL (1995) Cytogenetic studies of some Hypochaeris species (Compositae) from Brazil. Amer J Bot 82:369-375.

Ruas CF, Ruas PM and Cabral JR (2001) Assessment of genetic relatedness of the genera Ananas and Pseudananas confirmed by RAPD markers. Euphytica 119:245-252.

Samuel R, Stuessy T, Weiss H, Cerbah M and Siljak-Yakovlev S (1999) Molecular confirmation with ITS and trnL sequences of monophyly of Hypochaeris (Asteraceae) in South Amer- 
ica. In: Manitz H and Hellwig FH (eds) 14th Symposium Biodiversität und Evolutions Biologie.

Samuel R, Stuessy T, Tremetsberger K, Baeza CM and SiljakYakovlev S (2003) Phylogenetic relationships among species of Hypochaeris (Asteraceae, Cichorieae) based on ITS, Plastid TrnL intron, TrnL-F spacer, and matK sequences. Am J Bot 90:496-507.

Santala M, Power JB and Davey MR (1998) Genetic diversity in mung bean germplasm revealed by RAPD. P Breeding 117:473-478.

Schubert I and Wobus U (1985) In situ hybridization confirms jumping nucleolus organizing regions of Allium. Chromosoma 92:143-148.

Schwarzacher T, Ambros P and Schweizer D (1980) Aplication of Giemsa banding to orchid karyotype analysis. Plant Syst Evol 134:293-297.

Siljak-Yakovlev S, Bartiolo A, Roitman G, Barghi N and Mugnier C (1994) Étude caryologique de trois espèces d'
Hypochaeris originaires d' Argentine: H. chillensis, $H$. microcephala et H. megapotamica var. albiflora. Can J Bot 72:1496-1502.

Stebbins GL (1971) Chromosomal Evolution in Higher Plants. Edward Arnold, London, 216 pp.

Stuessy TF (2001) La filogenia y biogeografia de Hypochaeris (Asteraceae) en América del Sur. In: Seminars on Plant Ecology and Evolution, Universidad de Sevilla.

Welsh J and McClelland M (1990) Fingerprinting genomes using PCR with arbitrary primers. Nucleic Acids 18:7213-7218.

Williams JGK, Kubelik AR, Livak KJ and Rafalski JA (1990) DNA polymorphisms amplified by arbitrary primers are useful as genetic markers. Nucl Acids Res 18:6531-6535.

Wu J, Krutovskii KV and Strauss SH (1999) Nuclear DNA diversity, population differentiation, and phylogenetic relationships in the California closed-cone pines based on RAPD and allozyme markers. Genome 42:893-908.

Associate Editor: Marcelo Guerra 